Jeremias Gotthelf - der »Dichter des Hauses» 


\section{Werner Hahl}

\section{Jeremias Gotthelf - der »Dichter des Hauses«}

Verlag J. B. Metzler Stuttgart - Weimar 
Die Deutsche Bibliothek - CIP-Einheitsaufnahme

Hahl, Werner:

Jeremias Gotthelf, der "Dichter des Hauses" : die christliche Familie als literarisches Modell der Gesellschaft / Werner Hahl. - Stuttgart : Metzler, 1993 ISBN 978-3-476-00949-4

ISBN 978-3-476-00949-4

ISBN 978-3-476-03499-1 (eBook)

DOI 10.1007/978-3-476-03499-1

Dieses Wërk einschließlich aller seiner Teile ist urheberrechtlich geschützt. Jede Verwertung außerhalb der engen Grenzen des Urheberrechtsgesetzes ist ohne Zustimmung des Verlages unzulässig und strafbar. Das gilt insbesondere für Vervielfältigungen, Übersetzungen, Mikroverfilmungen und die Einspeicherung und Verarbeitung in elektronischen Systemen.

(c) 1994 Springer-Verlag GmbH Deutschland

Ursprünglich erschienen bei J. B. Metzlersche Verlagsbuchhandlung und Carl Ernst Poeschel Verlag GmbH in Stuttgart 1994 


\section{Vorwort}

Die vorliegende Arbeit wurde von der Fakultät für Sprach- und Literaturwissenschaft II der Universität München als Habilitationsschrift im Fach Neuere deutsche Literatur angenommen. Der Verfasser dankt den am Habilitationsverfahren beteiligten Lehrern und Kollegen für ihre Mühe und ihr förderliches Urteil. Namentlich seinem alten Lehrer Friedrich Sengle verdankt das Buch mehr, als jemals nachgewiesen werden könnte. Wolfgang Frühwald, Klaus Kanzog und Wolfgang Martens haben aufgrund eigener interdisziplinärer Forschungen dieser in die Sozial-, Frömmigkeits- und Rechtsgeschichte ausgreifenden Untersuchung anregendes Interesse entgegengebracht. Hilfreichen Rat gaben die Rechtshistoriker Peter Landau, Sten Gagnér und HansJoachim Rückert (Hannover), sowie der Theologe und Germanist Hermann Timm, der auch die literaturgeschichtlichen Nebenwege der Theologie kennt. Die Deutsche Forschungsgemeinschaft hat das Entstehen der Arbeit mit einem Habilitandenstipendium gefördert, wofür der Verfasser hier noch einmal seinen herzlichen Dank ausspricht. Sachkundige Hinweise und freundschaftliche Aufmunterung kamen stets von Alberto Martino (Wien) und Ernst Fischer (München). Rémy Charbon (Genf) hat dem Verfasser sein ausführliches und sorgfältiges Urteil über das Typoskript mitgeteilt. 


\section{Inhaltsverzeichnis}

\section{Teil: Die Uli-Romane. Ökonomie und Frömmigkeit}

im Leben der Hausgenossen

Die geschichtliche Frage, auf die der Roman Uli der Knecht antwortet. ................. 15

Rezeptionsgeschichtliche Hinweise. "Epoche der Dorfgeschichten « ................................. 15

Die Frage nach den sozialen Grundlagen des freiheitlichen Staates.

Erwartungen an den bäuerlichen Mittelstand ............................................................ 21

Tendenz zur Restauration der Familie. Gotthelf als »Dichter des Hauses« und sachliterarische Parallelen

Moritz von Lavergne-Peguilhen: das Dienstverhältnis als sozial erweitertes

Familien- und Liebesverhältnis

William Löbe: Erziehung der Dienstboten zur Spar- und Enthaltsamkeit,

damit sie billiger und doch reich werden

Geistliche Beiträge zur Erneuerung des Dienstwesens ............................................ 37

Johann Gottfried Hofmann: für eine steuerliche Begünstigung des sganzen Hauses ‘...... 41

Das Gesinderecht als Teil des Familienrechts ............................................................ 43

Uli der Knecht. Die Christliche Ökonomik als Roman .............................................. 46

Didaktischer Handlungsaufbau: Unterweisung im Dienen .............................................. 46

Ulis Weg in die familiale Gesellschaft: Aufstieg oder Eintritt? Die sozialethische

Erweiterung des Familienbegriffs bei Gotthelf

Uli der Knecht und die traditionelle christliche Lehre vom Haus: 1. Die Rezeption

der »Haustafeln « des Neuen Testaments

Der christliche Hausvater als Berner Bauer ........................................... 52

Religiöse Gleichheit und soziale Annäherung der Stände ............................................... 54

Soziales Vertrauen als Form des Glaubens. Die Ursünde des Mißtrauens .................... 56

Konvergenz der sozialen Interessen von Herr und Knecht ........................................ 62

Soziale Freiheit und Gleichheit. Mit einem Exkurs über Joh. v. Müller und Friedr. Schleiermacher

Uli der Knecht und die traditionelle christliche Lehre vom Haus: 2. Die christliche

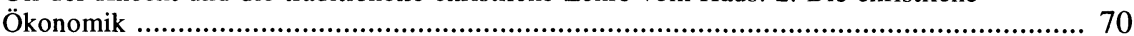

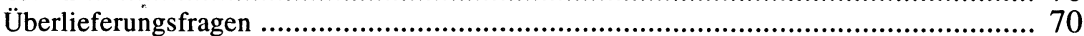

Justus Menius: Verteidigung des Privateigentums. Grobe Auffassung von Zucht .......... 73

Franciscus Philippus Florinus: Entfaltung von Gottesfurcht und sozialer Liebe

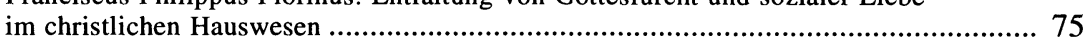

Germershausen und Krünitz: religiöse Zucht als Ausbeutungsinstrument ....................... 79

Zwei literarische Spiegelungen der Norm Familienliebe. Das Verhältnis von religiöser

Norm und erfahrungsgemäßer Psychologie ................................................................... 83

Vrenelis Charisma und die Initiation der neuen Dienstherrschaft ...................................... 87

Die Verjagung des Händlers ........................................................................................... 94

Wie Uli der Pächter gebessert wird. Von böser Natur, Hauskreuz

und Erlösung …………………………............................................................... 100

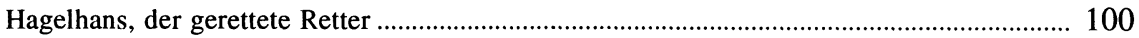

Ein heidnischer Schutzgott im christlichen Roman? ............................................... 100

Mit eigenen und fremden Sünden beladen ............................................................ 104

Erlöst mit Hilfe der Frommen............................................................................... 106

Ulis Rettung, eine providentielle Veranstaltung …….................................................... 110 
Hagelhans als Funktionär eines Bekehrungsrituals ......................................... 110

Endzeit der altbäuerlichen Ordnung und Psychologisierung des Gottvertrauens .......... 112

Providentia specialis .............................................................................. 114

Zum Gegensatz zwischen herber Zucht und fetter Erbschaft ................................ 116

2. Teil: Dialektischer Spielraum in Gotthelfs theologischem Denken. Ein Überleitungskapitel .......................... 119

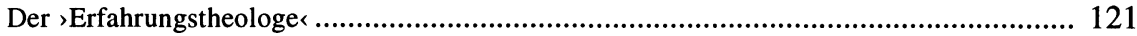

Unionsgedanke und Lutherbild bei Gotthelf ...................................................... 127

Probleme der konfessionskundlichen Einordnung Gotthelfs ..................................... 132

>Freiheitlich und reformiert - > untertänig und lutheranisch`? .............................. 139

>Gesetzesstreng und reformiert ८ - >antinomistisch und lutheranisch ? ..................... 142

Eudämonismus bei Gotthelf ................................................................... 148

\section{Teil: Die schwarze Spinne. Ritualisierung der Gottesfurcht} beim Erzählen vom Haus und für das Haus

Rhetorisch-ritualisierendes Erzählen in der `Schwarzen Spinne «. 1. Problemstellung und texttheoretischer Exkurs

»Ästhetische« und »rhetorische « Interpretation der Schwarzen Spinne ........................... 157

Persuasive und ritualisierende Funktion rhetorischen Sprechens .................................... 163

Subsumtion beider Funktionen unter die Entgegensetzung

>Ritual vs. zweckrationale Handlung

Zum Kontrasttyp der rhetorischen Zweckhandlung (Persuasion) .................................... 172

Das pragmatische Programm: die Rede nach Absichten und Erfolgsbedingungen

kalkuliert gestalten, um verändernd zu wirken. - Lausbergs Einbeziehung

der Fest- oder Wiedergebrauchsrede ................................................................ 172

Motivation als Informationstypus der rhetorischen Zweckhandlung ......................... 175

Vorherrschaft des persuasiv-pragmatischen Rhetorikverständnisses auch im Barock.... 177

Zum Typus der rituellen Handlung allgemein .............................................................. 179

Das Ritual als kollektive Bestätigungshandlung .................................................... 179

Die ganzheitliche Gestalt des Rituals .................................................................. 181

Semantik des Ganzen ................................................................................. 182

Ganzheitliches Erlebnis, erlebbare Ganzheit des rituellen Vollzugs .................... 182

\section{Rhetorisch-ritualisierendes Erzählen in der \Schwarzen Spinneく. 2. Textanalysen}

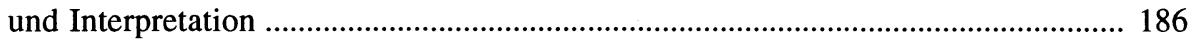

Feier der Schöpfung in der Eingangspassage ..................................................... 186

Vorüberlegung: Doppeldeutigkeit der Stilelmente in Richtung auf Persuasion und

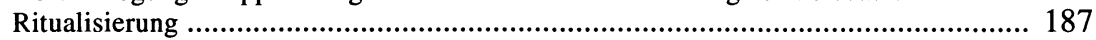

Analyse der performativen Präsentationssymbolik ................................................... 191

Rhetorische Ritualisierung der religiösen Furcht ........................................................... 195

Erbauliches Entsetzen ....................................................................................... 196

Die Spannung zwischen ritualisierender und diskursiver Darstellung ......................... 199

Gott und Teufel, die heilige Zweifaltigkeit ........................................................... 205

Den Schrecken christlich deuten. Ritualisierung der Glaubenshaltung durch 208

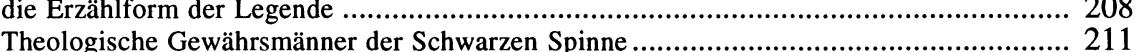

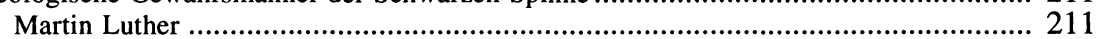


Ritual und Tabu als dominante Bedeutungsträger und Wirkungsmittel .......................... 222

Die Tabuzonen in der Welt der Binnenerzählung ........................................... 224

Verletzungen der Tabuzone Haus ................................................................. 224

Verletzungen der Tabuzone Gemeinde ........................................................ 225

Verletzungen der Tabuzone Person ........................................................ 228

Vom Teufel geküßt: Christine ............................................................ 228

Von der Spinne berührt: die Talbewohner ............................................. 231

Das halbfromme Brauchtum in der Rahmenerzählung ............................................ 234

>Die schwarze Spinne< - ein Dokument des literarischen Kulturkampfs ............... 240

Im Zentrum konservativer Utopie: das Haus ...................................................... 240

Sünden wider das $>$ Haus $<$ leiten die Katastrophe ein ........................................... 241

Die symbolische Geschichte der Schloß- und Hausbauten ...................................... 245

Die Kirche des 19. Jahrhunderts im Modernisierungsprozeß. Kirche und Haus

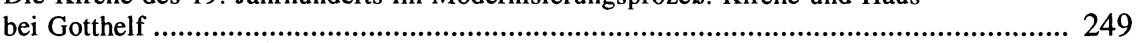

Der Volks(aber)glaube als religiöse Ressource ...................................................... 257

Die ,Wahrheit ‘ des Volksaberglaubens als Argumentationsfigur gegen die Aufklärung ..... 262

Für einen reformierten Kultus im Familien- und Nationalleben. Eine Idee

der Kulturkampfära

\section{Teil: Der Dichter des Hauses und der Rechtsstaat.} Erlebnisse eines Schuldenbauers

Kritik am liberalen Rechtsstaat von einer kirchlichen und theologischen Position........................................................................................ 277

Kritik am neuzeitlichen Staat ............................................................................... 277

Das Sündenfundament des liberalen Rechts- und Verfassungsstaats:

Begehrlichkeit und Hochmut ................................................................... 284

Gotthelf zu weiteren Problemen des Rechts ....................................................... 289

Aspekte der bernischen Rechtsgeschichte .................................................... 289

Kritik an privatrechtlichen Gesetzen altbernischer Herkunft ................................. 296

Nähe zur deutschrechtlichen Ideologie ................................................. 300

Rechtsstaatrichkeit - ein >notwendiges Übel ............................................... 306

\section{Gegen Rechtsstaat und politischen Radikalismus. Eine polemische Vermengung} in >Erlebnisse eines Schuldenbauers < ..................................................................... 309

Die Moral des Kleinbauern - die Schlinge, in der man ihn fängt ..................................... 311

Politischer oder relìgiöser Roman? Zweideutigkeit des Helden .................................... 320

Politischer oder religiöser Roman? Zweideutiges Motiv des Kreditmangels ...................... 325

Eigentumsfeindlichkeit radikaler Politik und Gesetzgebung? ......................................... 330

Das Schuldbetreibungsgesetz. »Geltstag « und »Güterabtretung « ............................. 331

Aufhebung der Geschlechtsbeistandschaft ........................................................ 335

Umfassende Kritik an der Autorität der Juristen ...................................................... 336

Personalistische Rechtsidylle: »Der Oberamtmann und der Amtsrichter « ................... 342

Hans Joggi gerettet, aber nicht die Idee des $>$ Hauses $₫$ ! ................................................ 346 
I. Die Uli-Romane. Ökonomie und Frömmigkeit im Leben der Hausgenossen .. 355

Die geschichtliche Frage, auf die »Uli der Knecht « antwortet .................................... 355

„Uli der Knecht«. Die christliche Ökonomik als Roman ............................................ 356

Wie Uli der Pächter gebessert wird. Von böser Natur, Hauskreuz und Erlösung ................ 360

II. Dialektischer Spielraum in Gotthelfs theologischem Denken.

Ein Überleitungskapitel

III. Die schwarze Spinne. Ritualisierung der Gottesfurcht beim Erzählen vom Haus und für das Haus

Rhetorisch-ritualisierendes Erzählen in der "Schwarzen Spinne«. 1. Problemstellung und texttheoretischer Exkurs

Rhetorisch-ritualisierendes Erzählen in der »Schwarzen Spinne«. 2. Textanalysen

und Interpretation

Rituale und Tabuverletzungen in der erzählten Welt der »Schwarzen Spinne«.

»Die schwarze Spinne« - ein Dokument des literarischen Kulturkampfs

IV. Der Dichter des Hauses und der Rechtsstaat. »Erlebnisse eines Schuldenbauers «

Kritik am liberalen Rechtsstaat von einer kirchlichen und theologischen Position Gegen Rechtsstaat und politischen Radikalismus. Eine polemische Vermengung in »Erlebnisse eines Schuldenbauers«

Literaturverzeichnis 